\title{
Development of a Remote Automatic Weather Station with a PC- based Data Logger
}

\author{
Roneel V. Sharan \\ School of Engineering and Physics, University of the South Pacific, Suva, Fiji \\ sharan_r@usp.ac.fj
}

\begin{abstract}
This paper presents the development of a prototype weather station to measure the following weather data: air temperature, relative humidity, dew point, wind speed, and rainfall. The weather station, which has been designed fon remote operation, performs automatic or unmanned measurements of weather data and transmits it wirelessly to a PC for logging and display by means of a graphical user interface. The remote station is powered using solar energy through a battery which also stores charge for a 24-hour operation of the system. Experimental results show that the measured data is quite consistent with those obtained by similar weather measurement devices.
\end{abstract}

Keywords: automatic weather station (AWS), solar energy, air temperature, relative humidity, dew point, wind speed, rainfall@ata logging

\section{Introduction}

Generating electricity through renewable energy sources such as solar energy, wind energy, and hydropower are on the rise globally. However, before such projects take shape, a key preliminary step is gathering and analysis of associated weather data, such as solar radiation, wind speed, and rainfall, at prospective location(s) to determine the viability and sustainability of the project. Insufficjent studies or assessments may eventually result in the project being aneconomical, such as in [1].

This leads to the problem of finding suitable weather measurement devices with the least of hassles in obtaining weather data considering most prospective sites are remotely located and measurements carre $\alpha$ out for long periods to cater for changing weather patterns over different seasons. Most low-cost weather measurement devices are hand-held and unsuitable for such work while the sophisticated ones are quite expensive [2]. In the work reported in this paper, final year electrical and electronic engineering students developed a low-cost automatic weather station (AWS) for such an application.

An AWS provides automated weather data measurements unlike the manually operated tradnional weather stations and have advantages such as consistency in data measurement, greate frequency of data acquisition, operable in all weather throughout the year, and can be installed in remote locations [3]. It finds applications in many areas such as agriculture and environmental monitoring [4], climate change and weather forecasting [5], amongst others. An AWS is normally powered using solar and/or wind energy since they are often remotely located. The weather data that an AWS measures depends on its application but can have sensors equipped to measure air temperature, humidity, rainfall, wind speed, wind direction, atmospheric pressure, solar radiation while some advanced ones are capable of measuring cloud height, thunderstorms, soil temperature at different heights, and terrestrial temperature 
$[3,5,6]$. An AWS offers features such as data collection, data storage, and wireless data communication with GSM/GPRS modules preferred these days as they provide high data communication range [6,7].

The AWS developed in this work consists of two units: the remote weather station and the main weather station as illustrated in Figure 1. The remote weather station measures the weather data and wirelessly transmits the weather data to the main weather station for display and logging. It has been designed to measure some common weather data and these are air temperature, relative humidity, dew point, wind speed, and rainfall. Since the measurement unit is to be remotely located, it is powered using solar energy. PIC16F877, the microcontroller used for this work, is the main controller on the remote station which interfaces with all the sensors. It handles data acquisition and data transmission using the transmitter unit. It is also used for receiving data using the receiver unit at the main weather station before communicating data to the PC through the RS232 serial port where the Matlab software reads the data for data logging and display through a graphical user interface (GUI).

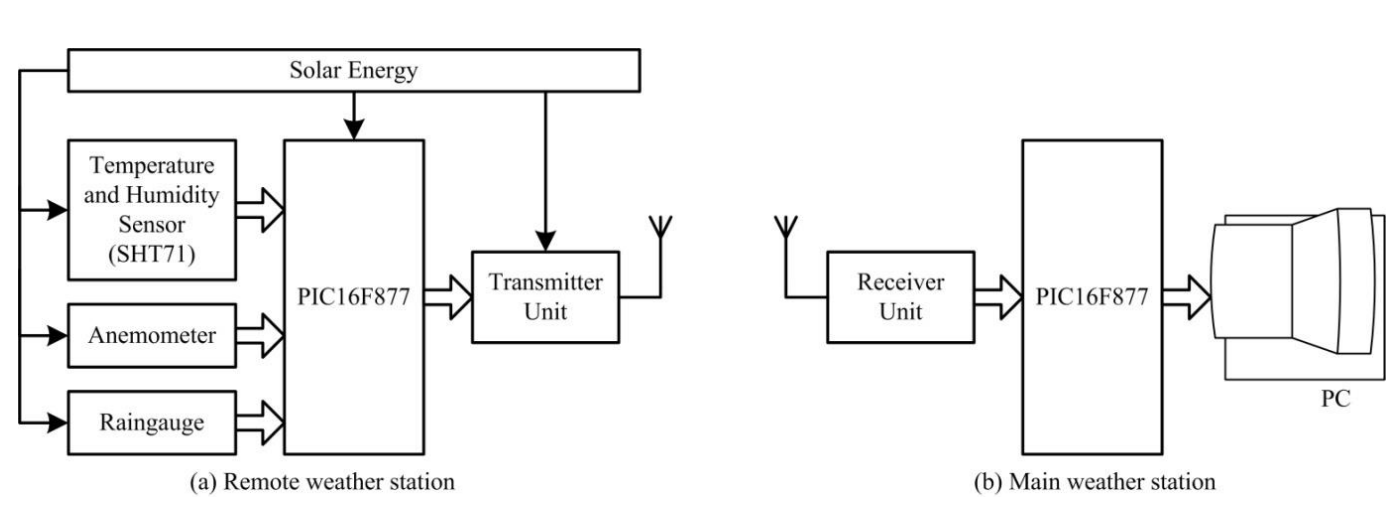

Figure 1. System overview

The rest of the paper S arranged as follows: Section 2 and 3 look at the development of the remote and main weather stations, respectively; experimentations performed and the results are presented in Section 4; followed by conclusion and future recommendations in Section 5.

\section{Remote Weather Station}

The remote unit has been developed to be deployed at the location where the weather data has to be measured. The unit, which has a maximum power consumption of approximately $720 \mathrm{~mW}$, is designed to have fully automatic operation using a PIC16F877 microcontroller and is powered using solar energy through a $12 \mathrm{~V}$ rechargeable sealed lead acid battery. The battery is charged during the daytime by the $15 \mathrm{~W}$ weatherproof amorphous solar panel using a solar charge controller. It has a fixed inclination of approximately $18^{\circ}$ facing north, based on the latitude of $18^{\circ} 00^{\prime \prime} \mathrm{S}$ for its test location.

In an ideal case, the remote unit can be located anywhere from a few hundred meters to several kilometers from the main weather station. However, in the development of this prototype, a $433 \mathrm{MHz}$ RF transmitter/receiver module already available in-house was used with plans to expand the range of operation later. This wireless communication module offers a range of about $100 \mathrm{~m}$ and 4-bit of data communication at a time. This means that each 16-bit of weather data, to an accuracy of two decimal places, is communicated to the main weather station in four transmissions. 


\subsection{Air Temperature and Relative Humidity}

The SHT71 sensor is utilized for measurement of air temperature and relative humidity. SHT71 is a four-pin digital sensor which has less energy consumption, temperature range of $40^{\circ} \mathrm{C}$ to $123.8^{\circ} \mathrm{C}$, and relative humidity range of $0-100 \%$. For temperature measurement, it offers a typical resolution, accuracy, and repeatability of $0.01{ }^{\circ} \mathrm{C}, \pm 0.4^{\circ} \mathrm{C}$, and $\pm 0.1^{\circ} \mathrm{C}$, respectively. Similarly, for relative humidity measurement, the typical resolution, accuracy, and repeatability are $0.05 \%, \pm 3.0 \%$, and $\pm 0.1 \%$, respectively.

The temperature and relative humidity values are also used to approximate the dew point for the temperature range $-40^{\circ} \mathrm{C}$ to $50^{\circ} \mathrm{C}$ as given in [8] as

$$
D=T_{n} \frac{\ln \left(\frac{H_{R}}{100 \%}\right)+\frac{m T}{T_{n}+T}}{m-\ln \left(\frac{H_{R}}{100 \%}\right)-\frac{m T}{T_{n}+T}}
$$

where $D$ is the dew point, $T$ is the temperature, $H_{R}$ is the relative humidity while, for the temperature range $-40^{\circ} \mathrm{C}$ to $0^{\circ} \mathrm{C}, T_{n}=272.62^{\circ} \mathrm{C}$ and $m=22.46$, and for the temperature range $0^{\circ} \mathrm{C}$ to $50^{\circ} \mathrm{C}, T_{n}=243.12^{\circ} \mathrm{C}$ and $m=17.62$. The dew point value is calculated after receiving the air temperature and relative humidity values at the pain weather station to reduce the amount of data communication between the two stations.

The serial clock input (SCK) and serial data (DATA) pins of the sensor are connected as inputs to PIC16F877 and used for reading the data values

\subsection{Wind Speed}

For measurement of wind speed, the inspeed yortex wind sensor is utilized. This rugged anemometer has a high quality 3-cup rotor pressed on a stainless steel shaft which can handle speed from 3 to over 125 miles per hour (or 1.34 to over 55.88 meters per second, $\mathrm{m} / \mathrm{s}$ ). It uses a reed/magnet switch which provides one pulse per rotation and the latest edition also comes with a sapphire bearing to mimimize wear. Conversion of pulses to wind speed is easily carried out as 1 pulse per second orresponds to 2.5 miles per hour (or $1.1176 \mathrm{~m} / \mathrm{s}$ ).

The external interrupt function of PIC16F877 is used to detect each pulse while the internal timer is used to time the pulse using which the wind speed is calculated as

$$
W=\frac{1}{T_{w}} \times 1.1176
$$

where $W$ is the wind speed in $\mathrm{m} / \mathrm{s}$ and $T_{w}$ is the period of a pulse in seconds.

\subsection{Rainfan}

A tipping bucket type rain gauge (OSK 7181-T) is used to measure the amount of rainfall. Every $0.2 \mathrm{~mm}$ of rainfall fills a bucket enough to tip about the fulcrum and this is converted to a digital signal using a reed switch with the external interrupt function of PIC16F877 used to read this trigger. The rainfall value is set to zero every time the rainfall data is transmitted but the rainfall data for the whole day is tallied up at the main weather station.

\section{Main Weather Station}

The main weather station consists of a PC, PIC16F877 microcontroller, and the receiver unit. PIC16F877 receives the weather data using the receiver unit and then this data is 
communicated to the PC through the serial port. The dew point value is automatically calculated after receiving the temperature and relative humidity values. The user gets access to the system using a Matlab based GUI, shown in Figure 2.

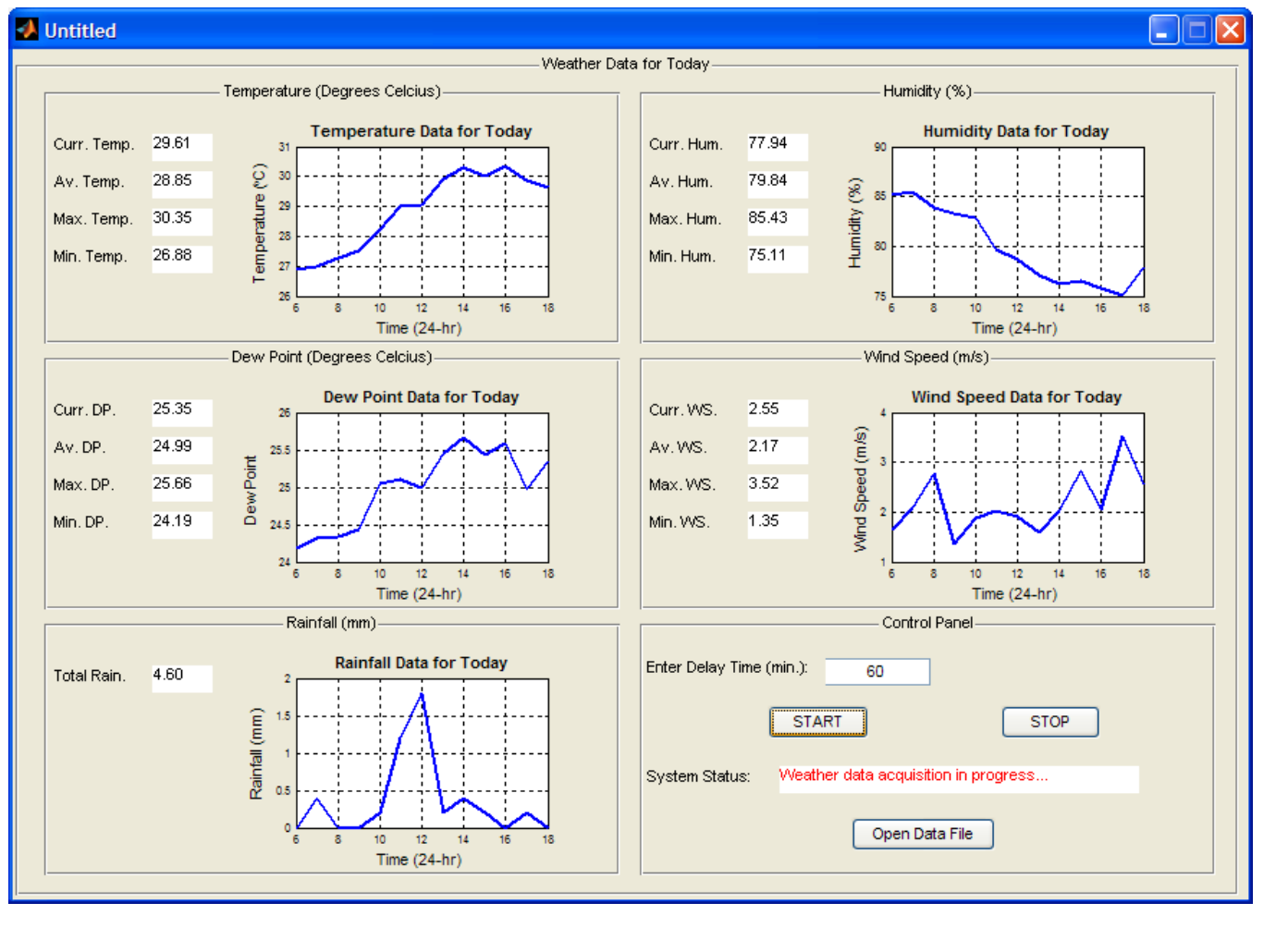

Figure 2.Developed GUI

A full set of weather data can be feceived in 15 seconds or less which is relatively fast considering that most applications Tequire weather data to be logged every hour or so. In the current setup, data communication is carried out continuously in real-time. However, the user has the option of choosing how often the data will be read by the PC for logging and display. The user enters this value in minutes and clicks on START to start the weather data acquisition process. The acquired data is analyzed and the GUI displays the current, average, maximum, and minimun values of air temperature, relative humidity, dew point, and wind speed together with the total rainfall for the day. A plot of the acquired weather data at each time interval is also shown in the GUI.

In addition, the weather data for each day is saved after every acquisition together with the time at which the data was acquired. The saved data is in ASCII format as an $m \times 6$ matrix where $m$ is the number of weather data set acquired for the day and the 6 columns constitute the five weather data and the time at which the data was acquired. The weather data for each day is saved in a separate file with each file created automatically where the filename corresponds to the date as "Weather_Data dd-mm-yyyy".

The user also has the option to stop the weather data acquisition process at anytime by interrupting the routine using the STOP button. Another added feature, executed through the Open Data File button, allows the user to open the weather data file for the current day without interrupting the weather data acquisition process. 


\section{Experimentation and Results}

Experimentations were carried out to measure weather data using the developed weather station and the results compared against weather data obtained through other sources. In the first phase of experimentations, temperature, relative humidity, and dew point measurements were carried out every hour over an 18 hour period with the results shown in Figures 3, 4, and 5 respectively.

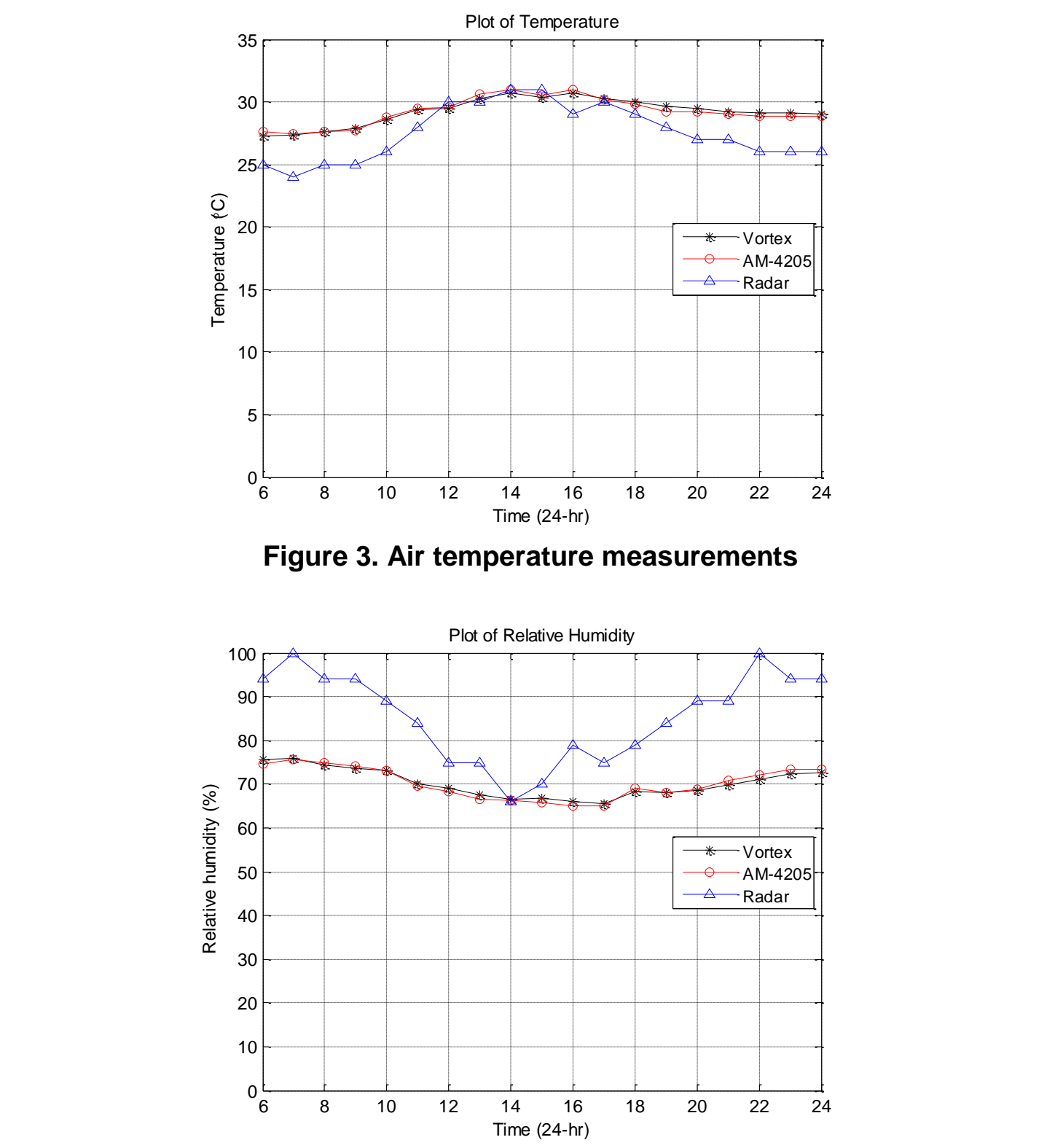

Figure 4. Relative humidity measurements 


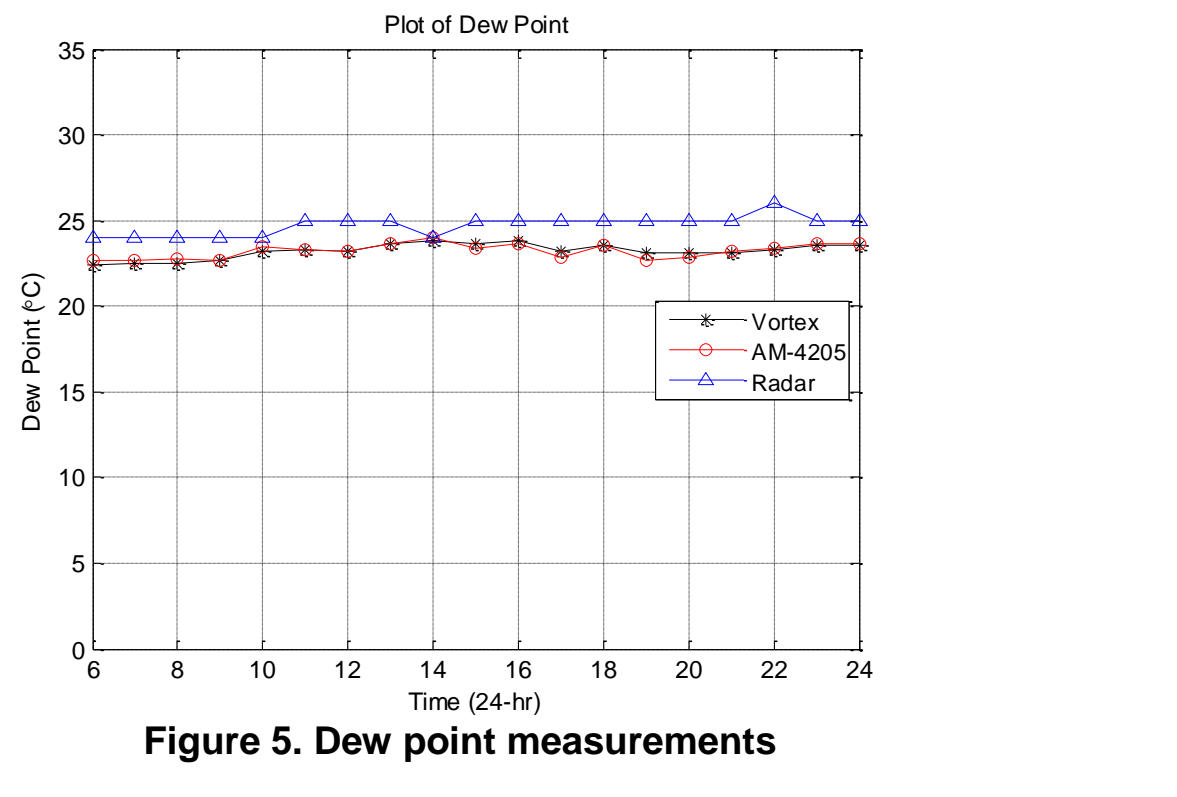

The results were compared to readings obtained using LUTRONAM-4205, a temperature, relative humidity, and wind speed measuremen device giving readings in digital format in various units. Data from a local radar station nocated approximately $20 \mathrm{~km}$ away were also obtained and plotted. The weather data from the rada was found to differ to some extent which is believed to be largely due to theing in a different environment. However, the weather data measured using SHT71/and AM-4205 was close in each case with an absolute average difference of $0.69 \%, 0.94 \%$, and $0.67 \%$ for temperature, relative humidity, and dew point respectively.

In the next experimentation, air speed measurements using the vortex anemometer were compared to measurements obtained with the AM-4205 anemometer. Unlike temperature, relative humidity, and dew point values, wind speed values are always changing. However, constant win speed is important in this experimentation as it is difficult to measure wind speed at exactly the same time asing two anemometers. With the unavailability of a suitable wind tunnel, which youd have been ideal for this experiment as it can provide constant airflow, an industriâ blower was used. It was powered using a variable voltage source so that comparisons can be done at different wind speeds.

The two anemometers were placed at the same position at $10 \mathrm{~cm}, 20 \mathrm{~cm}$, and $30 \mathrm{~cm}$ in front of the blower. The measurements obtained, as shown in Figure 6, had an average difference of about $5.7 \%$. This variation is largely believed to be due to the irregularity in the experimental setup as it is extremely difficult to position both the anemometers at the same location in front of the blower and maintain a constant airflow. However, the results do show a high degree of uniformity. 


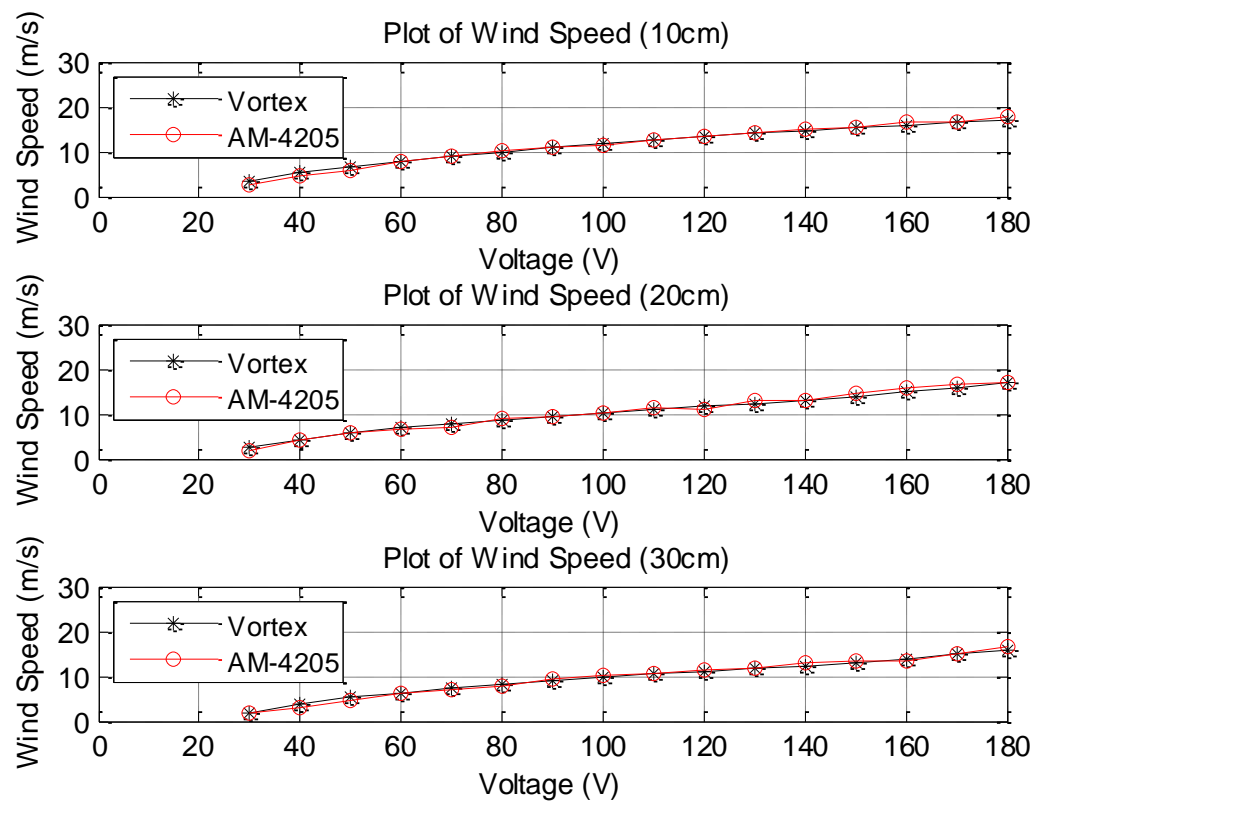

Figure 6. Wind speed measurements

\section{Conclusion and Future Work}

The prototype AWS, if eventuated into finished product, can be a great asset for weather data monitoring especially for renewable energy projects which require weather data measurements at remote locations. The remgte measurement system, wireless data communication, data logging and display, and good conformity of measured weather data to those obtained using a similar measurement device would make this an ideal choice.

A number of future works are being planned to increase the applications and suitability of this work. More rigorous experiments are required to test the suitability of the solar panel with fluctuating weather conditions and weather proofing the electrical and electronic units. Transfer of data over GSM/GPRS networks using respective modules for greater coverage and range is being looked al could also be eventually used to provide weather data to subscribers as text messages on their mobile phones.

Measurement of more weather data such as soil temperature, solar radiation, wind direction, sunrise sunset, atmospheric pressure, etc is also being considered. With plans for expanding the range of weather data being measured, the power requirements will also increase for the remote unit. This could be catered for by modifying the operation of the system to save energy such as switching the power off to all the weather measurement device when weather data is not to be measured, except those that require continuous measurement such as the rain gauge. Other options such as solar tracking, employing backup battery, and connecting an additional solar panel may also be considered.

\section{Acknowledgements}

The author acknowledges all students who worked on this project at some stage during its development especially Mr. Lawrence Raju, Mr. Eloni Kalou, Mr. Savenaca Seniloli, Mr. Ashneel Kumar, Mr. Prashneel Prasad, Mr. Benjamin Chand, and Mr. Qays Mohammed. 


\section{References}

[1] M. Karan, "34m failure: FEA admits lack of study in wind farm project", The Fiji Times Online, (2009) August 25, http://www.fijitimes.com/story.aspx?ref=archive\&id=127996.

[2] C. Liu, H. Lee, J. Yang, J. Huang, Y. Fang, B. Lee and C. King, "Development of a long-lived, real-time automatic weather station based on WSN", In Proceedings of SenSys 2008, (2008), pp. 401-402.

[3] Australian Government - Bureau of Meteorology, "Automatic weather stations for agricultural and other applications”, (1995) (Updated 2005), http://www.bom.gov.au/inside/services_policy/pub_ag/aws/aws.shtml.

[4] G. Hoogenboom, B. P. Verma and E. D. Threadgill, "The development of the Georgia automated environmental monitoring network", Proceedings of the 1991 Georgia Water Resources Conference, (1991) March 9-20, Athens, Georgia.

[5] Australian Government - Department of Sustainability, Environment, Water, Population, and Communities, "Automatic Weather Stations", (2011) July 21, http://www.antarctica.gov.au/about-antarctica/factfiles/weather/automatic-weather-stations.

[6] R. Weerasinghe, M. S. M. Aroos, A. S. Pannila, M. K. Jayananda and D. U. J. Sonnadara, "Development of an automated weather station with remote data transmission capability", Annual research syniposium science, University of Colombo, (2011), http://www.cmb.ac.lk/?page_id=3569.

[7] X. Guo and Y. Song, "Design of automatic weather station based on GSM module", 2010 International Conference on Computer, Mechatronics, Control and Electronic Engineering (CMCE), yol. 5, (2010) August 24-26, pp. 80-82.

[8] Sensirion, Datasheet SHT7X Humidity and Temperature Sensor, Version 4.3, (2010) May.

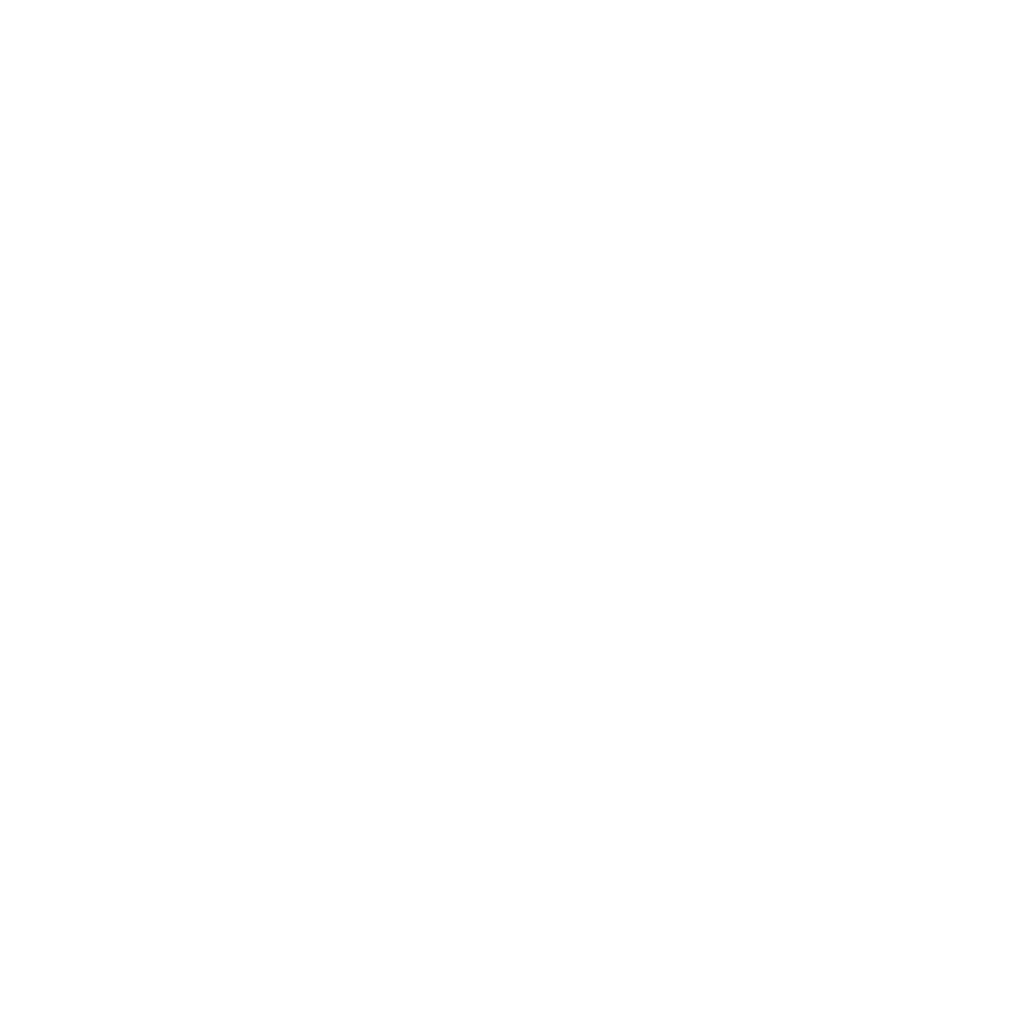

